\title{
Cost-Driven Informed Decisions Using Loss Analyses from Production Monitoring
}

\author{
Christina WINDMARK ${ }^{\mathrm{a}, 1}$ and Mikael SVENSSON ${ }^{\mathrm{b}}$ \\ ${ }^{a}$ Production and Materials Engineering, Lund University, Lund, 22100 Sweden \\ ${ }^{\mathrm{b}}$ LSAB Sverige Produktion AB, Långshyttan, 776 73, Sweden
}

\begin{abstract}
When embarking a cost reduction strategy, it is important to know what causes the costs, how the costs are connected to value adding and to non-value adding activities, and thereby conduct a knowledge-intensive production development. This paper present a method on how to connect costs to production losses and how they can relate to different cost factor groups. The method uses a digital tool that was designed in collaboration with a medium-sized tool manufacturing company, using several manufacturing operations in sequence.

The tool is designed to be used for management monitoring and for strategic decisions. The method uses a performance-based cost model for discrete part manufacturing and incorporates an approximation when dividing the calculated loss costs. To ensure the accuracy of the model a sensitivity analysis was conducted. The result shows that only smaller errors occur due to this approximation and amount to a few percent when extremely high losses are in effect. The novelty of the paper is the variation of the cost model, ensuring that costs can be divided on each of the cost factor groups and investigated performance parameter. In addition, the designed layout of the result presentation in the digital tool, is a further development of the previous presented production performance matrix, which contribute to a comprehensive overview used for production monitoring.
\end{abstract}

Keywords. Cost analysis; manufacturing; knowledgeable; decision support; valuebased

\section{Introduction}

Manufacturing companies are constantly struggling to be more competitive through improvements and cost reductions. In Western-European countries, such as Sweden, manufacturing strategies to reduce costs, increase quality and shorten lead-times are examples of such efforts. A trend existing for a long time is to allocate production of labour intensive operations to low cost countries [1]. However, the reasons to preserve or to reshore production are correlated to building and maintaining capabilities to create and sustain competitive advantages through deployment of key assets and resources, to preserve or develop a competitive manufacturing (CM) [2] organization. In both cases, costs are important, but the reason behind the strategy differs. When embarking a cost reduction strategy, it is important to know what causes the costs, how the costs are connected to value adding and to non-value adding activities [3], and thereby conduct a knowledge-intensive production development, to ensure that the improvement efforts actually reduce the costs as expected. Learning organizations are closely related to

\footnotetext{
${ }^{1}$ Corresponding Author. christina.windmark@iprod.lth.se
} 
knowledge-intensive organization or organization with absorptive capacity, where there are endeavour and capacity to learn, gain, and share knowledge. To achieve an organization with improvement initiatives it is important to have activities that spread and encourage knowledge together with an open and supportive environment [4]. One way to reach knowledge and understanding in a manufacturing organisation is to monitoring operations and use data and information to obtain insights [5].

This paper present a method on how data from production monitoring can be connect to production costs. The method includes production losses and how they are relate to different cost groups. The method uses a digital tool that was designed in collaboration with a medium-sized tool manufacturing company, using several manufacturing operations in sequence. The tool is designed to be used for management monitoring and for strategic decisions and aims to support a knowledge-intensive organisation from the work floor up to the management, facilitating sound decisions towards positive development in the organisation and its operations.

The objective was to develop a tool that:

1. Provide production costs that incorporate both losses and loss-free production

2. Provide cost of losses distributed on the three main cost drivers; material, personnel and equipment

3. Can be used for monitoring

4. Can be used for strategic decisions

5. Is valid for different production conditions

The tool aims to support decisions both in the workshop and in the company board room, with a goal to gain deeper insight on cost drivers and loss allocation, as costs and economic output is important for the manufacturing strategies.

This paper is structured as following; first, a literature study on performance measurement systems and systematic production analyses, followed by model presentation. To ensure that the model is valid for many different production conditions, a sensitivity analysis is conducted. The paper ends with discussions and conclusions of the results.

\section{Performance measurements system, Production performance matrix and Costs}

To gain knowledge and find suitable development paths in a production system, some sort of a well-developed performance measurements system (PMS) is needed, providing measures that can be used for continues improvements and monitoring [6]. The PMS is showed to be an important part to a company's product service system (PSS) [7], which in turn is valuable when aiming to reach strategic goals and for the company's competitiveness. However, the use of PMS is not unproblematic. Among other things, there are the interdependencies of different KPIs and measurements [8], increasing the likelihood of sub-optimization. There is also the trend of an increased number of measures [9][10] that could contribute to costly maintenance and use of the PMS together with deficient overview of the measures. The receiver and user of the information the measurements provide can be on different levels in a company [6][9], and hence the monitoring and actions in relation to the measures can be different, adding to the complexity. 
The Balanced Scorecard (BSc), one of the prominent tools in PMS [6], was introduced to complement financial performance measurers in industrial companies [11]. The original BSc has four different perspectives; financial, customer, internal business, and innovation and learning [11], in which the three last perspectives can be supported with use of the a Production Performance Matrix (PPM) [12] to evaluate and monitor a production system. To conduct production development it is important to understand root causes and not only treat the symptom but the reason to the problem. A working method, first develop for statistical process control and used for finding and solving problem in operations is the PDCA-cycle (Plan-Do-Check-Act) [13]. The PPM has been used in several different applications to evaluate and develop production operations and manufacturing systems [14][15]. The aim is to link effects and results to factors and root causes, providing a systematic way to monitor, analyse and evaluate an operation based on quality issues, downtimes, and speed rate losses.

Manufacturing execution systems (MESs) are widely used to gather data and measures for production monitoring and improvements such as Six-Sigma projects [16]. For highly automated industry with advanced machinery and sensors, data gathering can be made more or less automatic, but for industry with a lot of manual work the level of detail and accuracy can somewhat be lost due to manual data entering. To ensure the data quality, the input data need to be accurate and consistent, making the PPM a useable tool for this purpose [17]. Jacobsson and Skålén [17] used the PPM to divide cost of losses on factors and to report cost of production, cost of downtime, cost of material, and cost of labour.

An alternative to the PPM is the matrixes presented by Yamashina and Kubo [18]. The matrixes gives type of losses and if they affect the process or the system, casual losses, their links to result losses such as idling, indirect material losses, and energy losses, and cost related to the losses. In their publication they present how to conduct a detailed manufacturing analysis that provide cost of losses. The result is a cost function that relates to the overall equipment efficiency (OEE). The cost calculations are very similar to the one presented in Ståhl et al [19] but only provide the costs of losses, not the total manufacturing costs.

The main requirements of the model is to visualize the actual cost related to the four main cost drivers at the company, personnel, material, tools and equipment, incorporating losses. Both cost of value-adding and non-value adding activities, included losses are to be monitored. The use of fundamental measures that are not aggregated could lessen the occurrence of sub-optimizations, which make the PPM suitable for production monitoring.

\section{Model development and presentation}

The model incorporates cost of tools, equipment, material and personnel, and how quality losses, material waste, availability losses and speed rate losses affect each of these cost groups. For example, instead of only presenting the cost of personnel, the method present the total cost of personnel together with the cost of personnel due to quality problem, due to availability losses and due to speed rate losses. In this way a board or a production manager can get a better understanding of what's driving the costs and understand that not only the actual salary level is the factor for personnel costs, but also the efficiency and performance of the manufacturing operations. The aim is to promote 
knowledge driven decisions that drive the company to adopt strategies for performance and quality improvements.

The method uses a performance-based cost model for discrete part manufacturing and incorporates an approximation when dividing the loss costs [19], which is investigated through a sensitivity analysis, to ensure a reasonable accurate result. The tool is designed so that each process step in a production line is represented in a matrix providing the cost of each of the cost groups and performance parameters together with a percentage of the total costs. In addition, the tool provides information on the total cost of losses, cost for value adding activities, and number of parts/time frame included in the investigation.

\subsection{Cost parameters and equations used in the model}

The cost model used is presented in Ståhl et al [19], assuming that the utilization of the production is $100 \%$ during the analysed time frame. In the case of lower utilization, this is noted as downtime. The parameters used in the equations can be found in Table 1.

Table 1: Parameters in the cost formulas.

\begin{tabular}{ll}
\hline Parameter & Explanation \\
\hline $\mathrm{k}_{\mathrm{A}}$ & Cost of purchased tools (for one product) \\
\hline $\mathrm{k}_{\mathrm{B}}$ & Cost of purchased workpiece materials (for one product) \\
\hline $\mathrm{k}_{\mathrm{CP}}$ & Hourly machine costs (running) \\
\hline $\mathrm{k}_{\mathrm{CS}}$ & Hourly machine costs (idling) \\
\hline $\mathrm{k}_{\mathrm{D}}$ & Personnel costs per hour \\
\hline $\mathrm{N}$ & Number of produced items \\
\hline $\mathrm{N}_{0}$ & Number of produced items with correct quality \\
\hline $\mathrm{q}_{\mathrm{B}}$ & Share of material waste \\
\hline $\mathrm{q}_{\mathrm{P}}$ & Speed rate loss \\
\hline $\mathrm{q}_{\mathrm{Q}}$ & Quality ratio loss \\
\hline $\mathrm{q}_{\mathrm{S}}$ & Downtime rate \\
\hline $\mathrm{t}_{0}$ & Ideal cycle time \\
\hline $\mathrm{T}_{\mathrm{su}}$ & Setup time \\
\hline
\end{tabular}

The cost equation used to calculate the total part cost in one production station is presented in equation 1. The total cost presented in equation 1 entails four cost factors; Tools (A), Materials (B), Equipment (C), and Personnel (D) as stated with the brackets A-D. 


$$
\begin{aligned}
& k=\left[\frac{k_{A}}{\left(1-q_{Q}\right)}\right]_{A}+\left[\frac{k_{B}}{\left(1-q_{B}\right)\left(1-q_{Q}\right)}\right]_{B} \\
& +\left[\frac{k_{C P}}{60 \cdot N_{0}} \cdot\left(\frac{t_{0} \cdot N_{0}}{\left(1-q_{Q}\right)\left(1-q_{P}\right)}\right)+\frac{k_{C S}}{60 \cdot N_{0}}\right. \\
& \left.\cdot\left(\frac{t_{0} \cdot N_{0} \cdot q_{S}}{\left(1-q_{Q}\right)\left(1-q_{S}\right)\left(1-q_{P}\right)}+T_{s u}\right)\right]_{C} \\
& +\left[\frac{k_{D}}{60 \cdot N_{0}} \cdot\left(\frac{t_{0} \cdot N_{0}}{\left(1-q_{Q}\right)\left(1-q_{S}\right)\left(1-q_{P}\right)}+T_{s u}\right)\right]_{D}
\end{aligned}
$$

To calculate the cost of losses, approximations have been made according to equation 2-10. The equations will only provide and approximately correct answers as the loss parameters are in the denominator providing and inverse relation between them and the cost. However, the functions presented in equation 2-10 assume a linear relation. The error of this assumption will be further explored in section 4 . In the functions, the total cost of a factor group (tool, material equipment and personnel) is stated and the cost associated with the cost when excluding the parameter in question is subtracted. The parameters investigated in connection to the four factor groups are material waste share, quality ratio losses, downtime ratio losses and speed rate losses.

Cost of quality losses connected to tools and tooling systems

$$
\frac{k_{A}}{\left(1-q_{Q}\right)}-k_{A}
$$

Cost of material waste losses

$$
\frac{k_{B}}{\left(1-q_{Q}\right)\left(1-q_{B}\right)}-\frac{k_{B}}{\left(1-q_{Q}\right)}
$$

Cost of quality losses in workpiece material

$$
\frac{k_{B}}{\left(1-q_{Q}\right)\left(1-q_{B}\right)}-\frac{k_{B}}{\left(1-q_{B}\right)}
$$

Cost of quality losses connected to equipment

$$
\begin{aligned}
& \frac{k_{C S}}{60 \cdot N_{0}} \cdot\left(\frac{t_{0} \cdot N_{0} \cdot q_{S}}{\left(1-q_{Q}\right)\left(1-q_{S}\right)\left(1-q_{P}\right)}\right)+\frac{k_{C P}}{60 \cdot N_{0}} \cdot\left(\frac{t_{0} \cdot N_{0}}{\left(1-q_{Q}\right)\left(1-q_{P}\right)}\right)- \\
& \frac{k_{C S}}{60 \cdot N_{0}} \cdot\left(\frac{t_{0} \cdot N_{0} \cdot q_{S}}{\left(1-q_{S}\right)\left(1-q_{P}\right)}\right)-\frac{k_{C P}}{60 \cdot N_{0}} \cdot\left(\frac{t_{0} \cdot N_{0}}{\left(1-q_{P}\right)}\right)
\end{aligned}
$$


Cost of quality losses connected to personnel

$\frac{k_{D}}{60 \cdot N_{0}} \cdot\left(\frac{t_{0} \cdot N_{0}}{\left(1-q_{Q}\right)}+T_{s u}\right)-\frac{k_{D}}{60 \cdot N_{0}} \cdot\left(t_{0} \cdot N_{0}+T_{s u}\right)$

Cost of availability losses connected to equipment

$\frac{k_{C S}}{60 \cdot N_{0}} \cdot\left(\frac{t_{0} \cdot N_{0} \cdot q_{S}}{\left(1-q_{S}\right)}+T_{s u}\right)$

Cost of availability losses connected to personnel

$\frac{k_{D}}{60 \cdot N_{0}} \cdot\left(\frac{t_{0} \cdot N_{0}}{\left(1-q_{Q}\right)\left(1-q_{S}\right)\left(1-q_{P}\right)}+T_{s u}\right)-\frac{k_{D}}{60 \cdot N_{0}} \cdot\left(\frac{t_{0} \cdot N_{0}}{\left(1-q_{Q}\right)\left(1-q_{P}\right)}\right)$

Cost of speed rate losses connected to equipment

$$
\begin{aligned}
& \frac{k_{C S}}{60 \cdot N_{0}} \cdot\left(\frac{t_{0} \cdot N_{0} \cdot q_{S}}{\left(1-q_{Q}\right)\left(1-q_{S}\right)\left(1-q_{P}\right)}+T_{s u}\right)+\frac{k_{C P}}{60 \cdot N_{0}} \cdot\left(\frac{t_{0} \cdot N_{0}}{\left(1-q_{Q}\right)\left(1-q_{S}\right)}\right) \\
& \frac{k_{C S}}{60 \cdot N_{0}} \cdot\left(\frac{t_{0} \cdot N_{0} \cdot q_{S}}{\left(1-q_{S}\right)\left(1-q_{Q}\right)}+T_{s u}\right)-\frac{k_{C P}}{60 \cdot N_{0}} \cdot\left(\frac{t_{0} \cdot N_{0}}{\left(1-q_{Q}\right)}\right)
\end{aligned}
$$

Cost of speed rate losses connected to personnel

$$
\frac{k_{D}}{60 \cdot N_{0}} \cdot\left(\frac{t_{0} \cdot N_{0}}{\left(1-q_{P}\right)}\right)-\frac{k_{D}}{60 \cdot N_{0}} \cdot\left(t_{0} \cdot N_{0}+T_{s u}\right)
$$

\subsection{Model layout and input data.}

In the digital tool, data from each batch is logged. Number of entered parts/products, start and stop time together with the total downtime is registered, when the first part starts to be produced, giving the setup time, number of parts/products reaching the correct quality and the material waste associated with the actual product. The ideal cycle time for the produced product is registered in the system. From this information costs associated with the different losses can be estimated and presented as in Figure 1. The figure shows the accumulated costs in three production lines and a last summarizing table providing the cost of loss free production (value adding activities), the losses connected to value adding activities not utilized in the end product, total production costs and cost of losses associated to the four cost factors. In the white boxes to the left the total number of ingoing parts is presented and to the right the outgoing/finished number of parts. The number of part correspond to the selected batches analysed. In this way it is possible to select the extent of the analysis, either incorporate all product produced, a certain product group or product produced during a specified time period. 


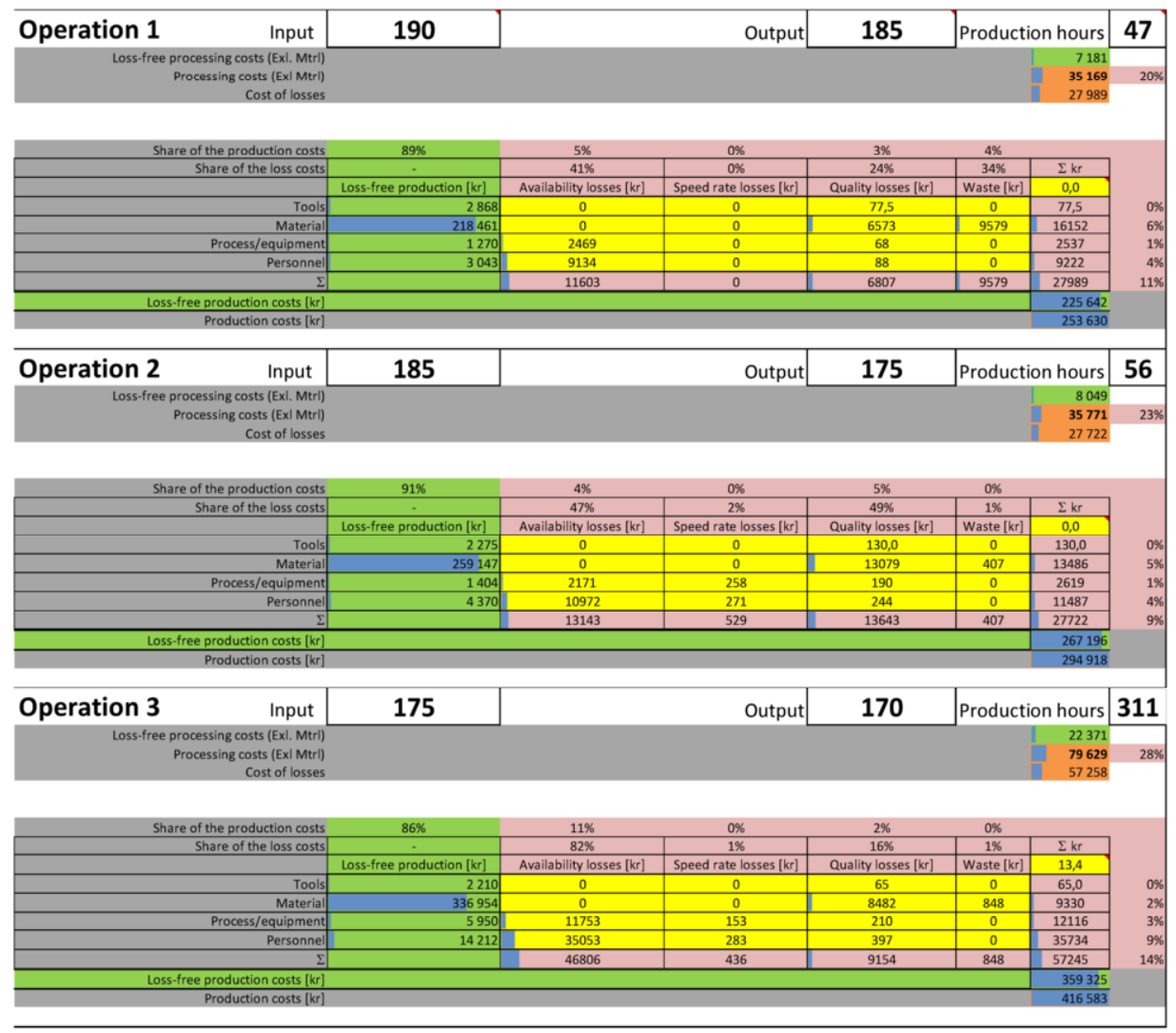

\begin{tabular}{|c|c|c|c|c|c|c|c|}
\hline Summary & 190 & & Output & 170 & \multicolumn{2}{|c|}{ Production hours } & 414 \\
\hline $\begin{array}{l}\text { Loss-free processing costs (Exl. Mtrrl) } \\
\text { Processing costs (Exi Mtrr) }\end{array}$ & & & & & & $\begin{array}{r}37600^{\circ} \\
150569\end{array}$ & $25 \%$ \\
\hline Cost of losses & & & & & & 112968 & \\
\hline Share of the production costs & 73\% & $17 \%$ & $0 \%$ & $7 \%$ & $3 \%$ & & \\
\hline Share of the loss costs & & $63 \%$ & $1 \%$ & $26 \%$ & $10 \%$ & $\Sigma \mathrm{kr}$ & \\
\hline & Loss-free production $[k r]$ & Availability losses $[k r]$ & Speed rate losses $[k r]$ & Quality losses $[k r]$ & Waste $[k r]$ & 13,4 & \\
\hline Tools & 7353 & $\frac{1}{0}$ & 0 & 272,5 & 0 & 272,5 & $0 \%$ \\
\hline Material & 267302 & 0 & 0 & 28134 & 10833 & 38968 & $9 \%$ \\
\hline Process/equipment & 8624 & 16393 & 411 & 468 & 0 & 17272 & $4 \%$ \\
\hline Personnel & 21624 & 55159 & 555 & 729 & 0 & 56443 & $14 \%$ \\
\hline & & 71552 & 965 & 29604 & 10833 & 112968 & $27 \%$ \\
\hline $\begin{array}{l}\text { Losses in added value in previous operation }[k \mathrm{kr}] \\
\text { Loss-free production costs }[k \mathrm{kr}] \\
\text { Production costs }[(k \mathrm{k}]\end{array}$ & & & & & & 303615 & \\
\hline
\end{tabular}

Figure 1. The interface of the result in the cost analysis tool.

\section{Sensitivity analysis}

A simplified sensitivity analysis was performed on the developed model. The total cost of losses for each of the factors Tools (A), Materials (B), Equipment (C), and Personnel (D) where computed using the above functions presented in equation 2-10 and compared with the associated cost in equation 1 minus the ideal cost as described in equation 11. The analysis provide the error for each cost factor (A-D) and the total error. In the 
sensitivity analysis the setup time $\mathrm{T}_{\mathrm{su}}$ is considered to be equal to 0 . Table 2 , contains the all values used in the analysis.

Table 2: Parameters and their values in the sensitivity analysis.

\begin{tabular}{lll}
\hline Parameter & Value & Unit \\
\hline $\mathrm{k}_{\mathrm{A}}$ & 15.5 & $\mathrm{kr}$ \\
\hline $\mathrm{k}_{\mathrm{B}}$ & 989 & $\mathrm{kr}$ \\
\hline $\mathrm{k}_{\mathrm{CP}}$ & 149 & $\mathrm{kr} / \mathrm{hrs}$ \\
\hline $\mathrm{k}_{\mathrm{CS}}$ & 97 & $\mathrm{kr} / \mathrm{hrs}$ \\
\hline $\mathrm{k}_{\mathrm{D}}$ & 286 & $\mathrm{kr} / \mathrm{hrs}$ \\
\hline $\mathrm{N}$ & 10 & $\mathrm{No.}$ \\
\hline $\mathrm{N}_{0}$ & $\mathrm{~N} /\left(1-\mathrm{q}_{\mathrm{Q}}\right)$ & $\mathrm{No.}$ \\
\hline $\mathrm{t}_{0}$ & 10 & $\mathrm{~min}$ \\
\hline $\mathrm{T}_{\mathrm{su}}$ & 0 & $\mathrm{~min}$ \\
\hline
\end{tabular}

$$
k=\left[k_{A}\right]_{A}+\left[k_{B}\right]_{B}+\left[\frac{k_{C P}}{60 \cdot N_{0}} \cdot\left(t_{0} \cdot N_{0}\right)+\right]_{C}+\left[\frac{k_{D}}{60 \cdot N_{0}} \cdot\left(t_{0} \cdot N_{0}\right)\right]_{D}
$$

The result from the analysis shows that the Material waste share $\mathrm{q}_{\mathrm{B}}$ does not contribute to any errors and that the cost factors Material and Tools do not contribute to errors. The analysis also show that losses only associated to downtime and quality does not contribute to errors. However, when speed rate losses occur in combination with quality losses or with two other loss parameters there are errors in the formulas. Below in Table 3, a selection from the stativity analyse is presented, showing the range of error occurring. The errors occur in C, D cost factors with a negative error in $\mathrm{C}$, and a positive error in D. High values in availability losses, $\mathrm{q}_{\mathrm{s}}$, contributes to an increased negative error in the Equipment costs $\mathrm{C}$. The occurrence of both positive and negative errors can contribute to a lower total level of error. However, for high levels of downtime losses, the error in $\mathrm{C}$ are larger than in $\mathrm{D}$, which can be seen by the negative errors occurring for high level losses in that parameter. The increase in error does also rapidly increase with high level losses (above $50 \%$ ). In the analysis Material waste and Quality losses cannot amount to no more than $100 \%$.

Table 3: Selected result from the sensitivity analysis.

\begin{tabular}{|c|c|c|c|c|c|c|c|c|c|c|}
\hline \multicolumn{4}{|c|}{ Loss parameters } & \multicolumn{5}{|c|}{ Errors in kr } & \multicolumn{2}{|l|}{ Cost } \\
\hline qв & qQ & qs & $\mathbf{q P}_{\mathbf{P}}$ & $\begin{array}{c}\text { A } \\
\text { error } \\
\text { in } \mathbf{k r}\end{array}$ & $\begin{array}{c}\text { B } \\
\text { error } \\
\text { in } \mathbf{k r}\end{array}$ & $\begin{array}{c}\text { C error } \\
\text { in } k r\end{array}$ & $\begin{array}{c}\text { D error } \\
\text { in } k r\end{array}$ & $\begin{array}{c}\text { Total error } \\
\text { in } k r\end{array}$ & $\begin{array}{l}\text { Production } \\
\text { cost in kr }\end{array}$ & Error in \% \\
\hline $0 \%$ & $90 \%$ & $0 \%$ & $90 \%$ & 0 & 0 & -2016.75 & 3857.14 & 1840.39 & 16387 & $11.23 \%$ \\
\hline $0 \%$ & $0 \%$ & $90 \%$ & $90 \%$ & 0 & 0 & 0 & 0 & 0 & 7385 & $0.00 \%$ \\
\hline
\end{tabular}




\begin{tabular}{|c|c|c|c|c|c|c|c|c|c|c|}
\hline $90 \%$ & $0 \%$ & $0 \%$ & $90 \%$ & 0 & 0 & 0 & 0 & 0 & 9721 & $0.00 \%$ \\
\hline $0 \%$ & $90 \%$ & $90 \%$ & $0 \%$ & 0 & 0 & 0 & 0 & 0 & 15607 & $0.00 \%$ \\
\hline $10 \%$ & $10 \%$ & $10 \%$ & $0 \%$ & 0 & 0 & 0 & 0 & $0 \%$ & 1214 & $0.00 \%$ \\
\hline $10 \%$ & $10 \%$ & $0 \%$ & $10 \%$ & 0 & 0 & -0.3 & 0.6 & 0.28 & 1215 & $0.02 \%$ \\
\hline $20 \%$ & $20 \%$ & $0 \%$ & $20 \%$ & 0 & 0 & -1.56 & 2.98 & 1.42 & 1536 & $0.09 \%$ \\
\hline $50 \%$ & $50 \%$ & $0 \%$ & $50 \%$ & 0 & 0 & -24.9 & 47.62 & 22.72 & 3913 & $0.58 \%$ \\
\hline $90 \%$ & $0 \%$ & $90 \%$ & $90 \%$ & 0 & 0 & 0 & 0 & 0 & 15467 & $0.00 \%$ \\
\hline $0 \%$ & $10 \%$ & $10 \%$ & $10 \%$ & 0 & 0 & -0.3 & 0.6 & 0.26 & 1113 & $0.02 \%$ \\
\hline $0 \%$ & $50 \%$ & $50 \%$ & $50 \%$ & 0 & 0 & -41.1 & 47.6 & 6.49 & 2372 & $0.27 \%$ \\
\hline $0 \%$ & $70 \%$ & $70 \%$ & $70 \%$ & 0 & 0 & -341.76 & 259.26 & -82.5 & 5506 & $-1.50 \%$ \\
\hline $0 \%$ & $90 \%$ & $90 \%$ & $90 \%$ & 0 & 0 & -13849.5 & 3857.1 & -9992.35 & 73852 & $-13.53 \%$ \\
\hline $50 \%$ & $50 \%$ & $20 \%$ & $20 \%$ & 0 & 0 & -28.96 & 47.62 & 18.66 & 3977 & $0.47 \%$ \\
\hline $50 \%$ & $50 \%$ & $50 \%$ & $20 \%$ & 0 & 0 & -10.28 & 11.9 & 1.62 & 3964 & $0.04 \%$ \\
\hline $5 \%$ & $5 \%$ & $50 \%$ & $50 \%$ & 0 & 0 & -2.16 & 2.51 & 0.34 & 1298 & $0.03 \%$ \\
\hline $5 \%$ & $5 \%$ & $90 \%$ & $50 \%$ & 0 & 0 & -9 & 2.51 & -6.49 & 2374 & $-0.27 \%$ \\
\hline $10 \%$ & $5 \%$ & $50 \%$ & $50 \%$ & 0 & 0 & -2.16 & 2.51 & 0.34 & 1354 & $0.03 \%$ \\
\hline $90 \%$ & $5 \%$ & $50 \%$ & $10 \%$ & 0 & 0 & -0.24 & 0.28 & 0.04 & 9628 & $0.00 \%$ \\
\hline $20 \%$ & $10 \%$ & $90 \%$ & $50 \%$ & 0 & 0 & -19 & 5.29 & 13.71 & 2703 & $0.51 \%$ \\
\hline $0 \%$ & $80 \%$ & $0 \%$ & $80 \%$ & 0 & 0 & -398.37 & 761.9 & 363.53 & 6380 & $5.70 \%$ \\
\hline $0 \%$ & $30 \%$ & $0 \%$ & $80 \%$ & 0 & 0 & -42.68 & 81.63 & 38.95 & 1823 & $2.14 \%$ \\
\hline $0 \%$ & $40 \%$ & $10 \%$ & $40 \%$ & 0 & 0 & -11.87 & 21.16 & 9.3 & 1744 & $0.53 \%$ \\
\hline $0 \%$ & $80 \%$ & $30 \%$ & $80 \%$ & 0 & 0 & -509.67 & 761.9 & 252.23 & 7065 & $3.57 \%$ \\
\hline $0 \%$ & $10 \%$ & $90 \%$ & $20 \%$ & 0 & 0 & -4.75 & 1.32 & -3.43 & 1914 & $-0.18 \%$ \\
\hline
\end{tabular}




\section{Discussion and conclusions}

Not surprisingly, the largest errors are obtained when there are high losses in quality, availability and production speed, where $90 \%$ in losses in each of the three parameters contribute to an error of $13.56 \%$. However, it is not likely that a production line has that high amount of losses. When investigating a more likely worst-case scenario with $20 \%$ material waste, $10 \%$ quality losses, $90 \%$ availability losses and $50 \%$ speed rate losses the error is found to amount to $0.51 \%$. As the $\mathrm{C}$ factor in combination with downtimes contributes to a negative error and the $\mathrm{D}$ factor to a positive, the internal error is higher than the total. However, in the case above the error in the $\mathrm{C}$ factor corresponds to an error of about $-0.7 \%$ and in the $\mathrm{D}$ factor $0.2 \%$. The sensitivity analysis show that the errors obtained when using the suggested formulas provide an accurate enough result and should be able to be used in production for cost analyses and production cost monitoring. At the company, where the model has been developed, much of the data gathering will be performed manually. Hence, the in-data errors will probably be higher than the error obtained using the suggested approximations.

The objective was to develop a tool that 1 . Provide production costs that incorporate both losses and loss-free production, 2. Provide cost of losses distributed on the three main cost drivers; material, personnel and equipment, 3. Can be used for monitoring, 4. Can be used for strategic decisions, and 5. Are valid for different production conditions. The digital tool includes both total, loss-free and cost related to losses and how these costs are related to the different cost factors tool, material, equipment and personnel. By showing the cost related to losses the potential for improvements is provided as the technical and organizational limitation of the operations. When estimating cost for new facilities or systems, this information can be used for cost estimations. The tool captures the losses induced for adding value to a product that does not meet the quality criteria in later operations. This supports the organization in implementing quality checks, when needed, and to further have more efficient utilization of resources. The tool also provides the cost of both material waste and quality losses where the first one support investigation of both product and operation design for better material utilization. In addition the tool support decision makers in seeing what type of losses that contribute to the highest cost for the operation in investigation. The tool contains 16 different combination of cost losses, probably not all are of high interest for a company and can therefore be excluded to minimize number of KPIs. The company must, based on their operation, decide on what to report and analyse.

The novelty of the paper is the variation of the cost model, ensuring that costs can be divided on each of the cost groups and investigated performance parameter. In addition, the designed layout of result presentation is a further development of the previous presented production performance matrix, which contribute to a comprehensive overview used in production monitoring. This paper contributes to knowledge-intensive product realization by presenting a structured method that provides information for decision makers, used for long and short-term strategies. The presented tool is designed to support evaluation and monitoring of three different production steps with different process conditions. The sensitivity analysis suggests that used approximations are sufficient and provide accurate enough results. However, the tool need more testing and further study at the company and by other users are needed to assure both userfriendliness and verification of the used cost models. A further development would also be to incorporate and specific report more cost drives/factors, such as materials handling and maintenance. 


\section{References}

[1] L. Bengtsson, R. von Haartman, and M. Dabhilkar, "Low-Cost versus Innovation: Contrasting Outsourcing and Integration Strategies in Manufacturing," Creat. Innov. Manag., vol. 18, no. 1, pp. 35-47, Mar. 2009, doi: 10.1111/j.1467-8691.2009.00510.x.

[2] R. Pal, S. Harper, and A. Vellesalu, "Competitive manufacturing for reshoring textile and clothing supply chains to high-cost environment A Delphi study," Int. J. Logist. Manag., vol. 29, no. 4, pp. 1147-1170, 2018, doi: 10.1108/IJLM-10-2017-0270.

[3] J.-E. Ståhl, Industriella tillverkningssystem: länken mellan teknik och ekonomi. 2005.

[4] A. Daghfous, "Absorptive Capacity and the Implementation of Knowledge-Intensive Best Practices," SAM Adv. Manag. J., vol. 69, no. 2, pp. 21-27, 2004.

[5] R. Ackoff, "From Data to Wisdom," J. Appl. Syst. Anal., vol. 12, no. 1, pp. 3-9, 1989.

[6] A. Neely, M. Gregory, and K. Platts, "Performance measurement system design A literature review and research agenda," 1995.

[7] J. H. Yang, "A balanced performance measurement scorecard approach for Product Service Systems," in 2009 International Conference on Business Intelligence and Financial Engineering, BIFE 2009, 2009, pp. 548-551, doi: 10.1109/BIFE.2009.129.

[8] M. L. Tseng, L. Divinagracia, and R. Divinagracia, "Evaluating firm's sustainable production indicators in uncertainty," Comput. Ind. Eng., vol. 57, no. 4, pp. 1393-1403, 2009, doi: 10.1016/j.cie.2009.07.009.

[9] A. Landström et al., "Present state analysis of business performance measurement systems in large manufacturing companies," PMA Conf. 2016, pp. 1-14, 2016.

[10] B. Gries and J. Restrepo, "KPI measurement in engineering design - A case study," ICED 11 - 18th Int. Conf. Eng. Des. - Impacting Soc. Through Eng. Des., vol. 1, no. August, pp. 531-537, 2011.

[11] R. S. KAPLAN and D. P. NORTON, "The Balanced Scorecard - Measures That Drive Performance," Harv. Bus. Rev., vol. 70, no. 1, pp. 71-79, 1992.

[12] J.-E. Ståhl, Industriella Tillverkningssystem del II. Lund Sweden: Material and Production Egineering, Lund University, 2009.

[13] W. E. Deming, "On Some Statistical Aids toward Economic Production,” INFORMS, vol. 5, no. 4, pp. $1-15,1975$.

[14] C. Möller and A. Sahleström, "Quality performance and cost analysis within customized productionTwo case studies from the worktop industry."

[15] C. Stål, J.-E. Ståhl, P. Gabrielson, and C. Andersson, "A production performance analysis regarding downtime and downtime pattern.," in Presented at the 22nd International Conference on Flexible Automation and Intelligent Manufacturing, FAIM., 2012, pp. 809-820.

[16] Y.-D. Hwang, "The practices of integrating manufacturing execution systems and Six Sigma methodology," Int J Adv Manuf Technol, vol. 31, pp. 145-154, 2006, doi: 10.1007/s00170-005-01640 .

[17] P. Jacobsson and E. Skålén, "Systematisk produktionsanalys - kostnadsberäkningar vid detaljtillverkning," Lund University, 2005.

[18] H. Yamashina and T. Kubo, "Manufacturing cost deployment," Int. J. Prod. Res., vol. 40, no. 16, pp. 4077-4091, 2002, doi: 10.1080/00207540210157178.

[19] J.-E. Ståhl, C. Andersson, and M. Jönsson, "A basic economic model for judging production development," in 1th Swedish Production Symposium, 2007. 